\title{
Bullying nas aulas de Educação Física: a percepção dos alunos no Ensino Médio
}

José Antonio Vianna a

Silvana Márcia de Souza ${ }^{a}$ Katarina Pereira dos Reis ${ }^{b}$

\section{Resumo}

Este estudo avaliativo do contexto escolar teve como objetivo verificar as percepções do bullying no Ensino Médio. Foram investigados 49 alunos, entre 17 e 19 anos de idade. Os dados confirmaram a ocorrência de bullying. Os meninos acreditam que o bullying ocorre com maior frequência em aulas separadas por sexo $(69,2 \%)$, sendo que $60,9 \%$ das meninas afirmam que o mesmo ocorre mais em aulas mistas. As práticas mais comuns são agressões verbais $(75,4 \%)$, agressões emocionais $(18,4 \%)$ e agressões físicas $(6,2 \%)$. Os investigados consideram legítima a ação do professor para a definição de direitos e obrigações, e para controlar os indivíduos desviantes.

Palavras-chave: Avaliação. Violência escolar. Bullying. Gênero.

\section{Introdução}

No ambiente escolar, as aulas de Educação Física são consideradas atraentes e prazerosas para os alunos. No entanto, existem casos em que os alunos resistem em participar das atividades propostas. Supõe-se que um dos fatores da resistência das alunas em participar de aulas mistas de Educação Física pode ser devido ao bullying por parte do gênero masculino. Todavia, há na literatura autores que acreditam que as aulas mistas são um amplo espaço para a aceitação e o desenvolvimento da pluralidade cultural (CHARLES, 2010), em que se defende o direito de todos os alunos participarem das aulas de Educação Física, independentemente de cor, etnia, religião, gênero, idade, entre outros.

\footnotetext{
a Universidade do Estado do Rio de Janeiro - IAFRS. Rio de Janeiro, Rio de Janeiro, Brasil

${ }^{b}$ Rede Euro Americana de Motricidade Humana. Rio de Janeiro, Rio de Janeiro, Brasil

Recebido em: 12 Ago., 2013

Aceito em: 26 Maio, 2014
} 
Nessa perspectiva, é papel de pesquisadores e professores da área encontrar alternativas para a não exclusão, além de repensar a prática pedagógica tornando-a acessível a todos os alunos, fazendo com que os mesmos entendam os direitos individuais e coletivos, e possam assumir atitudes e comportamentos de aceitação e respeito mútuo (JESUS; DEVIDE; VOTRE, 2008).

A ocorrência e a ampliação do bullying na sociedade contemporânea motivam o investimento em investigações para a compreensão dessa temática nas aulas de Educação Física escolar, com o propósito de solucionar a seguinte questão: qual a percepção dos alunos, no Ensino Médio, do bullying nas aulas de Educação Física escolar?

\section{0 contexto teórico}

Muitos são os estudiosos em busca da compreensão do fenômeno do gênero com foco no aprimoramento da qualidade da Educação Física na escola (DAÓLIO, 1995; SARAIVA, 1999; HAERTEL; GONÇALVES JÚNIOR, 2007; JESUS; DEVIDE; VOTRE, 2008; QUARESMA, 2010). Todavia, entre os diversos obstáculos enfrentados para o desenvolvimento da disciplina, há inúmeros questionamentos e posicionamentos em relação à separação das turmas de Educação Física por gênero. Alguns pensadores se posicionam de modo favorável, acreditando que assim é possível melhorar o nível das atividades (DURAND-DELVIGNE; DURUBELLAT, 2003). Outros pensam que a separação por sexo estaria favorecendo ainda mais atitudes sexistas (ABREU, 1995; SARAIVA, 1999; HAERTEL; GONÇALVES JÚNIOR, 2007; VIANNA, MOURA; MOURÃO, 2007).

Segundo Chrispino e Santos (2011), o conflito escolar é decorrente da democratização da escola, que passou a receber indivíduos de diferentes origens, valores e culturas. A Educação Física possui objetivos específicos, que contemplam a pluralidade e a diversidade, ou seja, de certo modo, privilegiam-se as aulas nas quais meninos e meninas participam juntos. No entanto, algumas jovens resistem em participar de atividades conjuntas com os meninos. Delgado, Paranhos e Vianna (2010) procuraram identificar os fatores que levam à não participação das alunas do Ensino Médio nas aulas de Educação Física escolar. Os autores levantaram informações sobre o relacionamento aluno/aluno e aluno/professor, a importância dada às aulas e o que poderia ser feito para melhorá-las. Obteve-se como resultado que, ao contrário do que é encontrado na literatura, a participação das alunas era satisfatória. No entanto, os autores verificaram que a discriminação por parte 
dos meninos, colegas de turma, era um dos fatores que contribuíam para a não participação de algumas jovens; porém, ainda assim, as alunas gostavam das aulas.

Esses dados abrem uma perspectiva ainda pouco estudada: o bullying como um dos fatores que levam à evasão feminina nas aulas de Educação Física escolar.

As diferentes manifestações de violência, nas quais o envolvimento de crianças e jovens como agentes ou vítimas, têm sido alvo de preocupação da sociedade contemporânea. Tornam-se cada vez mais frequentes as agressões realizadas por jovens nos diversos ambientes sociais e, em particular, no meio escolar.

A violência tem se tornado um dos grandes obstáculos ao processo ensinoaprendizagem, sendo a agressividade nas escolas um problema universal (LOPES; SAAVEDRA, 2004). Uma das formas mais visíveis da violência na sociedade é a chamada violência juvenil, assim denominada por ser cometida por pessoas com idades entre 10 e 21 anos. Os grupos em que o comportamento violento é percebido antes da puberdade tendem a adotar atitudes cada vez mais agressivas, culminando em graves ações na adolescência e na persistência da violência na fase adulta.

O ambiente escolar pode estar sujeito à reprodução da violência, traduzida em práticas efetivadas pelos próprios alunos, tais como agressões morais, físicas e psicológicas, e discriminações de gênero, raciais, políticas e de orientação sexual (OLIVEIRA; VOTRE, 2006; MALTA et al., 2010). A literatura tem classificado os comportamentos com diferentes níveis de violência como Bullying:

Chateações inoportunas ou hostis até fatos francamente agressivos, em forma verbal ou não, intencionais e repetidos, sem motivação aparente, provocados por um mais estudantes em relação a outros, causando dor, angústia, exclusão, humilhação e discriminação. (MALTA et al., 2010).

Cabe destacar que intimidações, humilhações, ameaças, difamações, opressões, discriminações, xingamentos, chacotas e tiranias não são exclusividades do ambiente escolar. Possivelmente, o bullying que ocorre no meio social extrapola para o meio escolar. Williams (2009) verificou que existe associação entre a violência intrafamiliar e o bullying no contexto escolar. Percebido como epidemia, investigadores de diversas áreas do conhecimento têm se debruçado sobre esse fenômeno em diferentes espaços, inclusive no ambiente do trabalho (PALÁCIOS; REGO, 2006). 
De forma geral, o bullying traduz relações assimétricas de poder entre o agente da agressão e a vítima, em que essa última apresenta dificuldades em se defender.

Nesse sentido, o bullying e a vitimização representam diferentes tipos de envolvimento em situações de violência durante a infância e a adolescência. O bullying se refere à forma de afirmação de poder interpessoal por meio da agressão. A vitimização ocorre quando uma pessoa é feita de receptor do comportamento agressivo de outra pessoa mais poderosa.

Bullying compreende todas as atitudes agressivas, intencionais e repetidas, que ocorrem sem motivação evidente, adotadas por um ou mais estudante contra outro(s), causando dor e angústia, sendo executadas dentro de uma relação desigual de poder. Essa assimetria de poder associada ao bullying pode ser consequência da diferença de idade, tamanho, desenvolvimento físico ou emocional, ou do maior apoio dos demais estudantes (LOPES; SAAVEDRA, 2004).

Os comportamentos agressivos que ocorrem nas escolas e que são tradicionalmente admitidos como naturais, sendo habitualmente ignorados ou não valorizados, tanto por educadores quanto pelos pais, são classificados como bullying escolar.

O bullying é classificado como direto, quando as vítimas são atacadas diretamente pelo agente, ou indireto, quando estes estão ausentes. São considerados bullying direto os apelidos, agressões físicas, ameaças, roubos, ofensas verbais ou expressões e gestos que geram mal-estar aos vitimizados. O bullying direto ocorre com uma frequência quatro vezes maior entre os meninos. O bullying indireto compreende atitudes de indiferença, isolamento, difamação e negação aos desejos, sendo mais adotadas pelas meninas (LOPES; SAAVEDRA, 2004).

Conforme a Associação Brasileira Multiprofissional de Proteção à Infância e à Adolescência (Abrapia), o bullying pode ser identificado por meio de algumas ações, como colocar apelidos, ofender, zoar, gozar, humilhar, excluir, agredir, roubar, entre outros aspectos. Estudo dessa associação observou, em pesquisa realizada com alunos de $5^{\mathrm{a}}$ a $8^{\mathrm{a}}$ série, em 11 escolas no Rio de Janeiro, que 16,9\% dos alunos foram vítimas de bullying, 10,9\% foram vítimas e autores, e 12,7\% foram somente autores (ASSOCIAÇÃO BRASILEIRA MULTIPROFISSIONAL DE PROTEÇÃO À INFÂNCIA E À ADOLESCÊNCIA, 2011).

Investigação sobre o bullying verificou correlação estatística deste com atitudes de mau comportamento e baixo desempenho escolar, enquanto as vítimas 
apresentaram desempenho escolar mais satisfatório. Outra pesquisa constatou a presença de bullying entre alunos de $5^{\mathrm{a}}$ e $8^{\mathrm{a}}$ séries, enquanto um terceiro estudo, com 1.075 alunos de $1^{\mathrm{a}}$ a $8^{\mathrm{a}}$ série do Ensino Fundamental de duas escolas públicas, identificou a prevalência desse fenômeno associado a 17,6\% dos sujeitos do sexo masculino, com hiperatividade e problemas de relacionamento. A intimidação mais prevalente foi a verbal, seguida da física, emocional, racial e sexual (FRANCISCO; LIBÓRIO, 2009).

\section{Metodologia}

A presente investigação se caracteriza por ser um estudo transversal, descritivo e exploratório. A amostra escolhida de forma intencional envolveu alunos do Ensino Médio em uma escola pública no município do Rio de Janeiro, que ao longo de sua trajetória escolar participaram de aulas de Educação Física (EF) mistas e aulas separadas por sexo. Todos os sujeitos participavam regularmente das aulas de EF duas vezes por semana, no período diurno. A escola, situada em bairro de classe média, reúne indivíduos de diferentes classes sociais.

Como instrumento de coleta de dados para a pesquisa, utilizou-se um questionário semiestruturado, dirigido aos alunos participantes, contendo questões abertas e fechadas, elaboradas especificamente para este estudo, respeitando a capacidade de verbalização do respondente (THIOLLENT, 1980). O questionário autoadministrado foi respondido por 26 sujeitos do sexo masculino e 23 do sexo feminino, entre 17 e 19 anos de idade. Solicitou-se aos participantes que respondessem às questões com base em suas experiências vividas no ambiente escolar.

Para a análise dos resultados, foi utilizada a estatística descritiva para o levantamento de categorias, que permitiram a interpretação dos dados e a comparação com a revisão literária (THIOLLENT, 1980).

A instituição de ensino recebeu um Termo de Informação à Instituição, pelo qual tomou conhecimento das condições da realização da pesquisa. Os sujeitos que concordaram em participar da investigação assinaram o Termo de Consentimento Livre e Esclarecido autorizando a utilização dos dados para fins científicos, com a garantia de não terem as suas identidades divulgadas.

O presente estudo atendeu às normas para a realização de pesquisa com seres humanos, Resolução 196/96, do Conselho Nacional de Saúde de 10/10/1996 
(BRASIL, 1996). A pesquisa foi aprovada no Conselho Departamental e no Núcleo de Ensino, Pesquisa e Extensão do IAFRS - UERJ.

\section{Resultados}

A maioria dos pesquisados $(81,6 \%)$ relatou preferir aulas de EF com a participação conjunta de meninos e meninas (77\% dos alunos e $87 \%$ das alunas), embora $23 \%$ dos meninos preferissem aulas separadas por sexo, enquanto $13 \%$ das meninas manifestaram a mesma preferência.

Questionados sobre a frequência com que o entrevistado ou algum colega já havia sido alvo de bullying, 38,8\% dos sujeitos afirmaram que nunca tiveram conhecimento de ocorrência de bullying nas aulas de EF. A soma da percepção de que o bullying ocorre raramente $(34,7 \%)$ com a percepção daqueles que se manifestaram indecisos em sua ocorrência - o que pode ser interpretado que o bullying tenha ocorrido - corresponde a 71,4\% das respostas. Esses dados levam-nos ao entendimento de que existe a prática do bullying nas aulas de EF, embora esta não ocorra sempre, como $6,1 \%$ dos respondentes acreditam ocorrer.

A prática do bullying parece ser mais frequente na percepção dos meninos - $11,4 \%$ dos entrevistados do sexo masculino indicaram que ocorre com frequência -, enquanto apenas uma aluna indicou que o bullying ocorre sempre.

Em contrapartida, 34,5\% dos meninos e 47,8\% das meninas informaram que nunca foram alvo ou perceberam a ocorrência de bullying nas aulas de EF. A Tabela 1 apresenta a autodeclaração dos entrevistados.

Tabela 1 - A percepção de meninos e meninas da ocorrência de bullying nas aulas de Educação Física

\begin{tabular}{|c|c|c|c|c|}
\hline \multirow{2}{*}{ Opções } & \multicolumn{2}{|c|}{ Meninos } & \multicolumn{2}{|c|}{ Meninas } \\
\hline & Freq. & $\%$ & Freq. & $\%$ \\
\hline Nunca & 09 & 34,5 & 11 & 47,8 \\
\hline Raramente & 10 & 38,8 & 07 & 30,4 \\
\hline Indeciso & 04 & 15,3 & 04 & 17,4 \\
\hline Com frequência & 03 & 11,4 & & \\
\hline Sempre & & & 01 & 4,4 \\
\hline Total & 26 & 100 & 23 & 100 \\
\hline
\end{tabular}

Fonte: Elaborado pelos autores (2013). 
No presente estudo, $83,7 \%$ dos pesquisados, em ambos os grupos, afirmaram que nunca deixaram de participar das aulas de EF por terem sofrido bullying $84,6 \%$ dos meninos e $82,6 \%$ das meninas. No conjunto de investigados, $15,4 \%$ dos alunos e $17,4 \%$ das alunas revelaram que ele próprio ou algum colega já deixou de participar das aulas devido ao bullying.

Os investigados identificaram o sexo masculino como uma das características predominantes do agressor $-95 \%$ dos meninos e $79 \%$ das meninas. A totalidade das meninas e $90 \%$ dos meninos indicaram também que esse indivíduo tende a ser o mais forte quando comparado ao vitimizado (mais fraco). O tamanho (altura) aparece como um fator favorável ao agressor, enquanto a vítima tende a ser menor. A maioria dos meninos $(71,4 \%)$ e das meninas $(83,3 \%)$ afirmou que o praticante é maior do que o agredido. Na percepção dos entrevistados, os agressores são sujeitos com mais idade do que os vitimizados - $95 \%$ dos meninos e $100 \%$ das meninas. O agressor é percebido pelos entrevistados como o mau aluno, opinião partilhada por $75 \%$ dos meninos e $81,2 \%$ das meninas.

Enquanto 69,2\% dos alunos acreditam que o bullying ocorre com maior frequência em aulas separadas por sexo, $60,9 \%$ das alunas afirmam que o mesmo ocorre mais em aulas mistas.

Na opinião dos participantes, a prática mais comum do bullying ocorre através de agressões verbais $(75,4 \%)$, seguidas das agressões emocionais $(18,4 \%)$ e das agressões físicas $(6,2 \%)$. Na Tabela 2, nota-se que a agressão física é menos presente na percepção feminina $(3,2 \%)$ do que na opinião masculina $(8,8 \%)$. Em contrapartida, a agressão emocional tem um vulto maior $(22,6 \%)$ na percepção feminina.

Tabela 2 - As agressões mais comuns na prática do bullying, na percepção dos alunos

\begin{tabular}{l|c|c|c|c}
\hline \multirow{2}{*}{ Opções } & \multicolumn{2}{c}{ Meninos } & \multicolumn{2}{c}{ Meninas } \\
\cline { 2 - 5 } & Freq. & $\%$ & Freq. & $\%$ \\
\hline Verbal & 26 & 76,5 & 23 & 74,2 \\
\hline Física & 03 & 8,8 & 01 & 3,2 \\
\hline Emocional & 05 & 14,7 & 07 & 22,6 \\
\hline Total & 34 & 100 & 31 & 100 \\
\hline
\end{tabular}

Obs.: Foram permitidas respostas múltiplas.

Fonte: Elaborado pelos autores (2013). 
Segundo os entrevistados, na maioria das vezes, a agressão nas aulas de EF se refere principalmente às habilidades dos que sofrem bullying ( $40 \%$ dos meninos e $45 \%$ das meninas). Próprio da adolescência, quando a reconstrução da autoimagem corporal exerce grande pressão nos jovens, a aparência ou a aceitação dos pares aparece como aspecto relevante na opinião de meninos (35,5\%) e meninas (37,5\%).

Na percepção dos meninos $(8,9 \%)$, a sexualidade parece ser mais notada pelos agressores do que na opinião das meninas (2,5\%) (Tabela 3$)$.

Tabela 3 - Características observadas nos vitimizados pelos agressores

\begin{tabular}{l|c|c|c|c}
\hline \multirow{2}{*}{ Opções } & \multicolumn{3}{c}{ Meninos } & \multicolumn{3}{c}{ Mreq. } \\
\cline { 2 - 5 } & Freq. & 2,2 & & $\%$ \\
\hline Racial & 01 & 8,9 & 01 & 2,5 \\
\hline Sexual & 04 & & & \\
\hline Econômica & & 35,5 & 15 & 37,5 \\
\hline Aparência & 16 & 13,4 & 06 & 15 \\
\hline Inteligência & 06 & 40 & 18 & 45 \\
\hline Habilidade & 18 & & & 100 \\
\hline Outros & & 100 & 40 &
\end{tabular}

Obs.: Foram permitidas respostas múltiplas.

Fonte: Elaborado pelos autores (2013).

Sem muita diferença entre as opiniões de meninos (20\%) e meninas (19,8\%), entre as formas mais comuns de agressão encontradas estão as ofensas verbais. Os grupos se diferenciam mais na percepção das agressões físicas $(7,6 \%$ dos meninos e $2,8 \%$ das meninas), da difamação (5,7\% dos meninos e $10,4 \%$ das meninas) e da exclusão dos vitimizados de atividades escolares (7,6\% dos meninos e 11,3\% das meninas) (Tabela 4).

A descrição dos principais motivos que levam um(a) aluno(a) a praticar o bullying foi marcada pela percepção masculina de que há sentido de superioridade e prepotência do agressor (dez respondentes), seguidas de um sentimento de insegurança ou pela busca de autoafirmação (seis entrevistados):

Uma pessoa que cause dano, seja emocional ou físico a outra e se sente bem com isso, normalmente o faz por querer se mostrar, aparecer para alguém. Nesse colégio particularmente, existe um grupo de idolatra a política de quanto mais babaca, mais descolada se é tais atitudes. Influenciam os mais novos, por exemplo, a praticar o bullying. (Masculino 24). 
Tabela 4 - Formas mais frequentes de agressão na percepção dos entrevistados

\begin{tabular}{l|c|c|c|c}
\hline \multirow{2}{*}{ Opções } & \multicolumn{3}{c}{ Meninos } & \multicolumn{2}{c}{ Meninas } \\
\cline { 2 - 5 } & \multicolumn{2}{c}{ Freq. } & \multicolumn{1}{c}{$\%$} & \multicolumn{1}{c}{ Freq. } \\
\hline Agressões Físicas & 06 & 5,6 & 03 & 2,8 \\
\hline Ameaças & 02 & 1,9 & & 67 \\
\hline Roubos & 21 & 20 & 21 & 19,8 \\
\hline Ofensas Verbais & 09 & 8,6 & 05 & 4,7 \\
\hline $\begin{array}{l}\text { Expressões e gestos que geram } \\
\text { mal-estar aos vitimizados }\end{array}$ & 20 & 19 & 19 & 17,9 \\
\hline Apelidar, ofender, zoar, gozar, humilhar & 06 & 5,7 & 11 & 10,4 \\
\hline Difamar & 08 & 7,6 & 12 & 11,3 \\
\hline Excluir de atividades escolares & 12 & 11,5 & 13 & 12,3 \\
\hline Excluir de atividades sociais & 01 & 0,9 & 04 & 3,8 \\
\hline Indiferença & 12 & 11,5 & 11 & 10,4 \\
\hline Isolamento & & & & \\
\hline Outros & 105 & 100 & 106 & 100 \\
\hline Total & & &
\end{tabular}

Obs.: Foram permitidas respostas múltiplas.

Fonte: Elaborado pelos autores (2013).

Os entrevistados do sexo masculino sugerem a ligação entre a prepotência manifestada e a insegurança do agressor:

Mascarar suas próprias inseguranças e 'pisar' em cima do outro para se sentir superior. (Masculino 25).

A noção de desajuste social devido à formação pessoal e social inadequada surge também na fala dos entrevistados, que abordaram tanto a opressão exercida pelos pais quanto a "falta de educação" que deveria ter sido ministrada no ambiente familiar.

Ao se sentir superior ao outro e ter uma vida que não desejaria, acarreta em um processo de desencadeamento que faz com que essa pessoa passe suas emoções equivocadamente nas outras, agindo de forma rude. (Masculino 15).

No entanto, também está presente na percepção dos entrevistados uma noção mais branda - "moleque" - do termo bullying.

Na verdade, o bullying é uma forma de dizer que a gozação na juventude/infância ocorre de forma excessiva. Mas quem faz o bullying na maioria das vezes não faz por mal, é só uma 
brincadeira. O problema é com quem a recebe, que vê muitos problemas nisso. (Masculino 11).

Diferente da percepção masculina, a opinião das jovens estabeleceu a insegurança e o desejo de autoafirmação como motivos predominantes para a prática do bullying (oito respostas), enquanto o sentimento de superioridade e a prepotência foram citados por cinco entrevistadas.

Segundo a participante n. ${ }^{\circ}$, "Um aluno que pratica o bullying é inseguro e tenta não mostrar isso ao fazer outras pessoas se sentirem inferiores". Os problemas de relacionamento social e aceitação podem estimular a prática de bullying:

Necessidade de aparecer, chamar a atenção, ser melhor. Na maioria das vezes também a pessoas que pratica é carente de amigos e precisa humilhar para chamar atenção (sic.). (Feminino 7).

A ação docente esperada pelos entrevistados do sexo masculino para a prevenção do bullying nas aulas está dividida entre a influência corretiva (repreender e penalizar) e a influência persuasiva (conversar e orientar).

As opiniões variam desde "Punição aos agressores (como por exemplo, tirar das aulas dos esportes que mais gostam), dar advertência, etc" (Masculino 9) até "Chamar o agressor para uma conversa, alegando que todos são iguais mesmo uns sendo mais habilidosos do que outros" (Masculino 22).

Ele (o professor) tem que se fazer presente em aula, convencendo de forma positiva a participação de todos os alunos. Deve reforçar sempre a importância da prática esportiva e fazer com que o aluno se foque nas aulas e não em perturbar seus colegas. (Masculino 15).

$\mathrm{Na}$ fala das jovens, a defesa da influência persuasiva é mais frequente. A defesa da repreensão e da penalização não é tão comum quanto entre os meninos.

O bullying sempre existiu e creio que continuará existindo, porém, pode ser reduzido através de palestras, conversas entre professor e aluno e orientação correta. É preciso obter uma educação correta desde criança, para que esta saiba quanto mal o bullying pode fazer. (Feminino 16). 
Observe-se que a percepção de que "Repreender o agressor quando estiver acontecendo o bullying e, caso não funcione, tomar medidas mais drásticas como chamar os responsáveis do bulinador ou castigar o mesmo com advertência (sic.)". (Feminino 16) também pode ser encontrada nas entrevistas.

O argumento presente na fala de sujeitos em ambos os grupos de que "[...] é necessário um trabalho especial de desenvolvimento de habilidades para que os menos aptos possam se inserir no grupo" (Masculino 3) e "[...] cuidar para que os menos habilidosos sejam incluídos [...]" (Feminino 21), embora sejam citados por um indivíduo em cada grupo, sugere que os indivíduos com menor habilidade nas atividades corporais e nos esportes são possíveis vítimas nas aulas de EF.

A percepção de que as causas do bullying estão além das esferas das aulas de EF foi manifesta pelos entrevistados, que apontaram falhas na formação familiar como um dos motivos e o ambiente escolar como um todo como espaço para essa ocorrência: "Depende do caso, afinal muitas vezes o bullying começa antes das aulas de educação física e são nessas aulas que se encontra a possibilidade de 'extravasar' e cometer tais ações". (Feminino 5).

\section{Discussão}

Os sujeitos pesquisados vivenciaram aulas mistas no primeiro segmento do Ensino Fundamental e aulas nas quais havia a separação dos alunos por sexo, a partir do segundo segmento até o Ensino Médio. Não foram identificadas, na percepção dos investigados, atitudes sexistas decorrentes desta separação, como sugerem investigações de Abreu (1995), Saraiva (1999), Haertel e Gonçalves Júnior (2007) e Vianna, Moura e Mourão (2007). Ao que tudo indica, a pedagogia de inclusão, aceitação e convivência harmoniosa de sujeitos de ambos os gêneros no espaço escolar com respeito às singularidades (CHARLES, 2010) tem alcançado os seus objetivos entre os participantes no estudo ao considerar que a maioria dos sujeitos prefere aulas com a participação conjunta entre meninos e meninas $(81,6 \%)$.

Nota-se que não parece haver incompatibilidade entre a separação de alunos por sexo nas aulas e a valorização da pluralidade, da diversidade e do respeito às diferenças. Os valores, atitudes e comportamentos para a convivência pacífica entre sujeitos provenientes de grupos culturais diferentes são fundamentais no ambiente escolar, local de acolhimento e convivência de indivíduos com características diversas. 
As informações coletadas sustentam as investigações de Pereira, Silva e Nunes (2009), Malta et al. (2010), Associação Brasileira Multiprofissional de Proteção à Infância e à Adolescência (2011), Grossi e Santos (2012), Scarpa et al. (2012), entre outros autores que apontam a ocorrência de bullying no ambiente escolar.

Existem evidências de que a vitimação durante a vivência em esportes gera baixa satisfação para a prática (SCARPA et al., 2012), o que pode levar à não participação. No entanto, a suspeita de Delgado, Paranhos e Vianna (2010) de que a evasão feminina nas aulas de EF pode ser devida ao bullying praticado por jovens do sexo masculino só se aplica à minoria das alunas que deixa de fazer as aulas.

As diferenças de habilidades motoras entre os alunos e as alunas, decorrentes das diferenças individuais e das oportunidades de socialização distintas, parecem explicar as percepções masculinas de que o bullying ocorre em aulas separadas por sexo, enquanto as jovens sustentam que as aulas mistas são mais propícias ao bullying. Na opinião dos investigados, nesta pesquisa, a agressão nas aulas de EF é provocada principalmente devido à pouca habilidade motora dos que sofrem bullying (percepção de $40 \%$ dos meninos e $45 \%$ das meninas).

As habilidades motoras exigidas em alguns esportes foram relatadas por alunas como motivos para a evasão nas aulas de EF no Ensino Médio (BETTI; LIZ, 2003; DUARTE; MOURÃO, 2007; MARTINELLI et al., 2006; ROSÁRIO; DEVIDE, 2008). Apesar de permitirem a expressão de desejos e aprenderem a negociar participações no espaço masculino, em aulas mistas, as meninas com habilidades motoras menos desenvolvidas ficam mais expostas às avaliações e críticas (GOELLNER, 2003); portanto, mais suscetíveis a chacotas, ofensas e humilhações. No entanto, se as aulas mistas têm sido motivo para a evasão de algumas jovens, a participação da maioria tem sido satisfatória (DELGADO; PARANHOS; VIANNA, 2010). Assim, ao retirar os conteúdos esportivos do currículo da EF, corre-se o risco de agradar a minoria e desagradar a maioria.

Costa et al. (2012) ressaltam a necessidade de reflexão sobre as estratégias e metodologias da EF face ao fenômeno do bullying. O lúdico e o lazer são os instrumentos sugeridos por Barros, Carvalho e Pereira (2009) para o desenvolvimento de competências sociais que contribuam na prevenção de brigas, conflitos e confusões no ambiente escolar. Segundo Fajardo et al. (2006), a análise do contexto sociocultural dos educandos é essencial no planejamento da intervenção pedagógica com foco na diminuição da violência escolar. O pressuposto de que 
os indivíduos praticantes de bullying provavelmente são oriundos de contextos sociais violentos deve ser considerado.

As práticas do bullying indicadas por Malta et al. (2010) foram observadas nesta investigação - humilhar, isolar e excluir foram as ações percebidas pelos investigados. Assim como em Pereira, Silva e Nunes (2009), ambos os grupos perceberam a agressão verbal como predominante na prática do bullying, seguida da agressão física. As agressões físicas são mais presentes no meio masculino, enquanto as meninas se utilizam mais de atitudes e comportamentos que afetam a vítima emocionalmente.

A percepção de que a agressão revela a insegurança do praticante de bullying encontra eco na pesquisa de Gutierrez et al. (2012), na qual os autores verificaram que os agressores são conscientes de que o bullying é incorreto, é considerado socialmente como maldade, censurável, injusto e impróprio; no entanto, justificam que a sua ação é mais um meio de autodefesa. Outra explicação plausível para o desvio ${ }^{1}$ são as justificativas do praticante - que são assumidas pelo mesmo como válidas -, nas quais o dano não é percebido como tal, mas como uma forma legítima de retaliação ou punição (BECKER, 2008).

Ao que tudo indica, os praticantes de bullying não se diferenciam de pessoas que acreditam que, para mudar a própria vida e a vida alheia, é necessário ter grandes poderes e realizações, para serem percebidos, ouvidos e respeitados, e se utilizam dos meios de que dispõem para alcançar seus objetivos. Esses sujeitos parecem não perceber que a autoridade e a liderança almejada devem ser provenientes de bons exemplos, cuidados, comprometimentos, respeito e de outros valores e atitudes positivas que são valorizadas socialmente. Em sua ação, os praticantes de bullying se aproximam da dominação carismática com caráter autoritário e imperativo encontrada em Weber (1981).

Os indivíduos aqui investigados argumentam que o agressor se vale de sua superioridade sobre a vítima. O perfil do agressor delineado pelos sujeitos pesquisados corresponde ao preconizado no estudo de Lopes e Saavedra (2004), o que reforça a representação de que a assimetria de poder entre o agressor e a vítima tem marcas físicas e sociais: o menino, o mais forte, o mais alto, o mau aluno. Conforme Espinheira e Jólluskin (2009) e Gutierrez et al. (2012), o gênero masculino apresenta mais vítimas e, simultaneamente, mais agressores.

${ }^{1}$ Becker (2008) apresenta um estudo abrangente e aprofundado da sociologia do desvio. 
Se as relações entre o agressor e a vítima do bullying podem ser tomadas como relações assimétricas de poder, a fala dos investigados sobre os motivos que levam à prática do bullying e suas sugestões dos procedimentos a serem adotados pelo professor para prevenir a sua ocorrência aparecem impregnadas da construção cultural que reconhece o poder do professor como um agente da instituição escolar responsável pela estruturação de direitos e obrigações, nesse contexto.

Sob a perspectiva de Weber (1981), o poder pode se manifestar na possibilidade de um ator social estar na posição de facultar a outro sujeito atender à sua vontade, mesmo contra resistência. O professor detém a autoridade que é uma modalidade de poder legitimada socialmente e exerce a dominação racional sobre os alunos no ambiente escolar. Essa última pode ser ampliada e aprofundada na medida dos seus atributos carismáticos e pessoais.

Porém, há de se observar que o papel do professor pode gerar efeitos tanto positivos - quando atua como agente mediador e favorece o reconhecimento do outro por meio do diálogo restaurador (GROSSI; SANTOS, 2012) - quanto negativos quando o mesmo passa a ser agente do bullying (TOGNETTA; VINHA, 2010).

Segundo Scott (2010), tanto a influência corretiva encontrada em Weber quanto a influência persuasiva de Foucault são formas de poder encontradas em ações cotidianas de poder interpessoal. Os alunos legitimam a dominação exercida pelo professor, atribuindo a esse agente a influência corretiva mediante o emprego de punições, por meio da força e da manipulação - mais presente na fala dos meninos - ou a influência persuasiva por meio de argumentos que façam perceber que algumas condutas são adequadas e outras não são - a preferência feminina.

Sob esta perspectiva, se propõe entender que os professores, como autoridades no ambiente escolar, são capazes de controlar os subordinados, ao moldar os interesses segundo os quais tanto ele quanto os alunos devem agir. Essa forma organizada de influência persuasiva funciona face ao comprometimento, à lealdade e à confiança no ambiente institucionalizado (escola). Assim, os investigados parecem recorrer ao poder institucionalizado para se contrapor às manifestações de ressentimentos, hostilidade ou retração de indivíduos que se comportam fora das normas, possivelmente como uma resistência ao poder institucionalizado. Galvão et al. (2010) chamam a atenção ao fato de que regras impostas pela instituição escolar, sem coerência em sua aplicação, também são fatores de deterioração do ambiente escolar. Há de se buscar alternativas que aliem liderança, competência técnica e compromisso da equipe escolar. 
Segundo a Sociologia do Desvio (BECKER, 2008), os sujeitos investigados estão situados com aqueles que criam as regras e rotulam os desviantes. Ao que tudo indica, o bullying é decorrente da interação entre a pessoa que o comete e aquelas pessoas que reagem ao mesmo. Há de se destacar que a aplicação da moralidade dos ativistas que ressaltam o bullying na escola tem sido intensificada nos últimos anos, despertando reações mais incisivas do que em outro momento.

A importância ética e moral do controle do que tem sido chamado de bullying, no ambiente escolar, não pode embaçar a percepção de que os praticantes são sujeitos desviantes das normas criadas por aqueles que fizeram as regras e obrigam aos demais a cumpri-las. E que nem todos os classificados como agressores se encaminham para um desvio maior - conhecedores ou não das normas sociais, os atores sociais não estão livres de pequenos desvios momentâneos.

Deve-se cuidar para que, na ansiedade de controlar os desvios no contexto escolar, a rotulação do sujeito praticante de bullying (realizada pela comunidade escolar) não contribua para moldar os alunos segundo a imagem construída por outros. Um efeito inesperado resultante da identificação pública do praticante pode ser a exclusão, o isolamento e outras atitudes antissociais que não contribuirão em nada para a transformação e a reintegração desse indivíduo. Passaria, então, a se cometer o bullying às avessas.

\section{Conclusões}

A avaliação do contexto escolar e a percepção dos seus atores podem lançar luz sobre as políticas e a pedagogia de combate ao bullying no ambiente escolar. A percepção de alunos no $3^{\circ}$ ano do Ensino Médio, do bullying nas aulas de Educação Física, foi construída a partir da avaliação de suas vivências no ambiente escolar ao longo dos anos de escolaridade. Na opinião dos estudantes, o bullying ocorre com pouca frequência nas aulas de EF e é um motivo para que apenas a minoria dos alunos deixe de participar das aulas. Os vitimizados correspondem a sujeitos que são importunados por indivíduos que se valem do seu maior tamanho e força. O agressor é tido como um estudante que não tem bom desempenho escolar e é caracterizado pelos escolares como um "mau aluno", que se considera superior ou deseja se afirmar sobre os demais.

A suspeita de que as aulas separadas por sexo podem estimular atitudes sexistas, não foi confirmada - apesar de as jovens informarem que a prática do bullying é mais frequente em aulas mistas. Os dados levantados parecem sustentar a hipótese 
de que a habilidade motora inferior de algumas meninas, quando comparada às habilidades de meninos, em aulas mistas, pode motivar "zoações" e ofensas verbais frequentes, que levam a constrangimentos e sofrimento emocional.

Não escapa da avaliação dos participantes, a percepção de que, se existem excessos e falta de controle nas atitudes e comportamentos do agressor, ocorre também a ausência de habilidade em lidar com conflitos e ameaças característicos da vida cotidiana, por parte do vitimizado.

Em contraposição ao poder do agressor sobre a vítima do bullying, os investigados destacam a dominação e o poder legitimado socialmente ao professor e à instituição escolar, que devem lançar mão dos modos restritivo e discursivo para a definição de direitos e obrigações, e o controle dos indivíduos desviantes.

Propõe-se investigar as racionalizações dos alunos praticantes de bullying e dos alunos vitimizados para ampliar e aprofundar o tema em pauta. A percepção de escolares do professor como praticante de bullying também merece ser mais bem investigada.

\section{Referências}

ABREU, N. G. Análise das percepções de docentes e discentes sobre turmas mistas e separadas por sexo nas aulas de educação física escolar. In: ROMERO, E. (Org.). Corpo, mulher e sociedade. Campinas: Papirus, 1995.

ASSOCIAÇÃO BRASILEIRA MULTIPROFISSIONAL DE PROTEÇÃO À INFÂNCIA E À ADOLESCÊNCIA - ABRAPIA. Programa de redução do comportamento agressivo entre estudantes. Rio de Janeiro. Disponível em: $<$ www.miniweb.com.br/Educadores/Artigos/.../bullying_abrapia.pdf $>$. Acesso: 18 jun. 2011.

BARROS, P. C.; CARVALHO, J. E.; PEREIRA, B. O. Um estudo sobre o bullying no contexto escolar. CONGRESSO NACIONAL DE EDUCAÇÃO - EDUCERE "Políticas e práticas educativas: desafios da aprendizagem, 9., 2009, Curitiba, Brasil. Anais... Curitiba: Champagnat, 2009. p. 5738-5757.

BECKER, H. Outsiders: estudos de sociologia do desvio. Rio de Janeiro: Jorge Zahar, 2008. 
BETTI, M.; LIZ, M. Educação Física escolar: a perspectiva das alunas de ensino fundamental. Revista Motriz, Rio Claro, v. 9, n. 3, p. 135-142, 2003.

BRASIL. Conselho Nacional de Saúde. Resolução $n^{\circ}$ 196, de 10 de outubro de 1996. Aprova as diretrizes e normas regulamentadoras de pesquisas envolvendo seres humanos. Diário Oficial [da] República Federativa do Brasil, Brasília, DF, out. 1996.

CHARLES, N. Gênero. In: SCOTT, J. (Org.). Sociologia: conceitos-chave. Rio de Janeiro: Zahar, 2010.

CHRISPINO, A.; SANTOS, T. C. Política de ensino para a prevenção da violência: técnicas de ensino que podem contribuir para a diminuição da violência escolar. Ensaio: Avaliação e Políticas Públicas em Educação, Rio de Janeiro, v. 19, n. 70, p. 57-80, 2011.

COSTA, T. P. et al. A função do educador físico no enfrentamento do fenômeno bullying no âmbito escolar. Perspectivas Online: Biológicas e Saúde, Rio de Janeiro, v. 2, n. 4, p. 28-40, 2012.

DAÓLIO, J. Da cultura do corpo. Campinas: Papirus, 1995.

DELGADO, D. M.; PARANHOS, T. L.; VIANNA, J. A. Educação Física escolar: a participação das alunas no ensino médio. Efdeportes, Buenos Aires, v. 14, n. 140, 2010. Disponível em: http://www.efdeportes.com/efd140/educacao-fisicaescolar-a-participacao-das-alunas.htm. Acesso em: 27 out. 2012.

DUARTE, C. P.; MOURÃO, L. Representações de adolescentes femininas sobre os critérios de seleção utilizados para a participação em aulas mistas de educação física. Movimento, Porto Alegre, v. 13, n. 01, p. 37-56, 2007.

DURAND-DELVIGNE, A.; DURU-BELLAT, M. Co-participação e construção do gênero. In: MARUANI, M.; HIRATA, H. (Org.) Homens e mulheres no mercado de trabalho. São Paulo: Senac, 2003. p. 101-110.

ESPINHEIRA, F.; JÓLLUSKIN, G. Violência e bullying na escola. Revista da Faculdade de Ciencias Humanas e Sociais, Lisboa, v. 6, p. 106-115, 2009. 
FAJARDO, I. N. et al. Pressupostos de uma avaliação de contexto existencial da violência escolar para o planejamento de condutas motoras educacionais voltadas para pré-adolescentes de classes de progressão. Ensaio: Avaliação e Políticas Públicas em Educação, Rio de Janeiro, v. 14, n. 50, p. 91-106, 2006.

FRANCISCO, M. V.; LIBORIO, R. M. C. Um estudo sobre bullying entre escolares do ensino fundamental. Psicologia: Reflexão e Crítica, Porto Alegre, v. 22, n. 2, p. 200-207, 2009. http://dx.doi.org/10.1590/S0102-79722009000200005.

GALVÃO, A. et al. Violências escolares: implicações para a gestão e o currículo. Ensaio: Avaliação e Políticas Públicas em Educação, Rio de Janeiro, v. 18, n. 68 , p. $425-442,2010$.

GOELLNER, S. V. A produção cultural do corpo. In: LOURO, G. L.; NECKEL, J. F.; GOELLNER, S. V. (Org.). Corpo, gênero e sexualidade: um debate contemporâneo na educação. Petrópolis: Vozes, 2003. p. 28-40.

GROSSI, P. K.; SANTOS, A. M. Bullying in brazilian schoools and restorative practices. Canadian Journal of Education, Canada, v. 35, n. 1, p. 120-136, 2012.

GUTIERREZ, R. et al. A study of mental attribuition toward bullying in students ages 10 to 16 through the SCAN Bullying Questionaire. Electronic Journal of Research in Educational Psychology, Espanha, v. 10, n. 2, p. 545-568, 2012.

HAERTEL, B.; GONÇALVES JÚNIOR, L. O gênero nas aulas de Educação Física: uma experiência em escola de ensino médio da cidade de São Carlos. In: CONGRESSO NACIONAL DE EDUCAÇÃO - EDUCERE: SABERES DOCENTES - EDIÇÃO INTERNACIONAL, 7., 2007, Curitiba. Anais... Curitiba: PUCPR, 2007. p. 1777-1789.

JESUS, M. L.; DEVIDE, F. P.; VOTRE, S. Apresentação e análise de trabalhos acerca da distribuição dos alunos por sexo nas aulas de Educação Física Escolar. Movimento, Rio Claro, v. 14, n. 2, p. 83-98, 2008.

LOPES, N. A. A.; SAAVEDRA, L. H. Diga NÃO para o Bullying. Rio de Janeiro: ABRAPIA, 2004.

MALTA, D. C. et al. Bullying nas escolas brasileiras: resultados da Pesquisa Nacional de Saúde do Escolar (PeNSE), 2009. Ciência \& Saude Coletiva, Rio de 
Janeiro, v. 15, n. 2, p. 3065-3076, 2010. Suplemento 2. http://dx.doi.org/10.1590/ S1413-81232010000800011. PMid:21049147

MARTINELLI, C. et al. Educação física no ensino médio: motivos que levam as alunas a não gosatarem de participar das aulas. Revista Mackenzie de Educação Física e Esporte, São Paulo, v. 5, n. 2, p. 13-19, 2006.

OLIVEIRA, F. F.; VOTRE, S. J. Bullying nas aulas de educação física. Movimento, Rio Claro, v. 12, n. 2, p. 173-197, 2006.

PALÁCIOS, M.; REGO, S. Bullying: mais uma epidemia invisível? Revista Brasileira de Educação Médica, Rio de Janeiro, v. 30, n. 1, 2006. http://dx.doi. org/10.1590/S0100-55022006000100001.

PEREIRA, B. O.; SILVA, M. I.; NUNES, B. Descrever o bullying na escola: estudo de um agrupamento de escolas no interior de Portugal. Revista Diálogo Educacional, Curitiba, v. 9, n. 28, p. 455-466, 2009.

QUARESMA, L. Violência escolar e de gênero. Revista do Departamento de Sociologia da FLUP, Porto, v. 20, p. 351-374, 2010.

ROSÁRIO, K. L.; DEVIDE, F. P. O discurso dos discentes concluintes do ensino médio sobre os saberes construídos na Educação Física escolar: uma nálise a partir da teoria de gênero. In: ENCONTRO FLUMINENSE DE EDUCAÇÃO FÍSICA ESCOLAR, 2008, Niterói. Anais... Niterói: DEF/UFF, 2008.

SARAIVA, M. C. Co-educação física e esportes: quando a diferença é mito. Ijuí: Unijuí, 1999.

SCARPA, S.; CARRARO, A.; GOBBI, E.; NART, A. Peer-victimization during physical education and enjoyment of physical activity. Perceptual and Motor Skills, Louisville, v. 115, n. 1, p. 319-324, 2012. http://dx.doi.org/10.2466/06.05.10. PMS.115.4.319-324. PMid:23033766

SCOTT, J. Poder. In: SCOTT, J. Sociologia: conceitos-chave. Rio de Janeiro: Zahar, 2010.

THIOLLENT, M. Crítica metodológica, investigação social e enquete operária. São Paulo: Polis, 1980. 
TOGNETTA, L. R. P.; VINHA, T. P. Até quando? Bullying na escola que prega a inclusão social. Educação: Revista do Centro de Educação UFSM, Santa Maria, v. 35, n. 3, p. 449-464, 2010.

VIANNA, A. J. C.; MOURA, D. L.; MOURÃO, L. Gênero e educação física escolar: uma análise das evidências empíricas sobre a discriminação e o sexismo. In: CONGRESSO BRASILEIRO DE CIÊNCIAS DO ESPORTE, 15., 2007, Recife. Anais...

WEBER, M. Ensaios de sociologia. Rio de Janeiro: Guanabara, 1981.

WILLIAMS, L. C. A. Violência intrafamiliar e intimidação entre colegas no ensino fundamental. Cadernos de Pesquisa, São Paulo, v. 39, n. 138, p. 995-1018, 2009. http://dx.doi.org/10.1590/S0100-15742009000300015.

\section{Bullying in Physical Education classes: the perception of students. \\ Abstract}

This evaluation study aimed to examine the perceptions of bullying in high school. We investigated 49 students aged 17 to 19 years. These data have confirmed the occurrence of bullying. The boys believe that bullying occurs more frequently in classes separated by gender (69.2\%); 60.9\% of the girls state that it occurs more often in mixed classes. The most common practices are verbal abuse (75.4\%), emotional abuse (18.4\%), and physical abuse (6.2\%). The students investigated consider legitimate the teacher's action to define rights and obligations to control deviant individuals.

Keywords: Evaluation. School violence. Bullying. Gender.

\section{Bullying en las clases de Educación Física: la percepción de los alumnos de enseñanza media}

\section{Resumen}

Este estudio evaluativo del contexto escolar tuvo como objetivo examinar las percepciones del bullying en la enseñanza media. Fueron investigados 49 alumnos, entre 17 y 19 años de edad. Los datos confirmaron la ocurrencia de bullying. Los chicos creen que el bullying se produce con más frecuencia en clases separadas por sexo (69,2\%) - el 60,9\% de las chicas dicen que el mismo 
ocurre con más frecuencia en las clases mixtas. Las prácticas más comunes son las agresiones verbales $(75,4 \%)$, emocionales $(18,4 \%)$ y fisicas $(6,2 \%)$. Los investigados consideran legítima la acción del maestro para definir los derechos y obligaciones y para controlar a los individuos desviantes.

Palabras-clave: Evaluación. Violencia escolar. Bullying. Género.

\section{Informações dos autores}

José Antonio Vianna: javianna@hotmail.com

Silvana Márcia de Souza: sillvolei@hotmail.com

Katarina Pereira dos Reis: katarinareis@ig.com.br 